\title{
Manfaatkan Kotoran Sapi Menjadi Kompos Untuk Tanaman Masa Pandemi Di Kelurahan Umbansari Kota Pekanbaru
}

\author{
Latifa Siswati*1, Rini Nizar $^{2}$, Anto Ariyanto ${ }^{3}$ \\ 1,2,3Fakultas Pertanian Universitas Lancang Kuning \\ *e-mail: latifasiswati@unilak.ac.id ${ }^{1}$
}

\begin{abstract}
Farming is currently carried out with organic farming, so compost is needed to replace chemical fertilizers. The use of fertilizers made from organic raw materials is highly recommended, because fertilizers made from compost can help help nutrients in the soil, besides compost can also be made from raw materials that are around our environment.. Using compost can help farmers save on production costs, because compost can be made from unused raw materials. For example, compost derived from cow dung, usually does not have a price and benefits, it turns out that it can be used as a raw material for making compost so that this utilization can reduce production costs that are usually incurred by farmers. The purpose of this service is to provide knowledge to partners that it turns out that the livestock waste they cultivate can be used as raw material for composting so that livestock waste in the form of cow dung can be overcome and can also help farmers reduce costs incurred for farming which is also they do. Compost made from cow dung is very helpful in soil fertility and can be seen directly by its benefits for plants and soil. Conclusion The use of cow dung into compost is to reduce livestock manure waste. This community service activity is concluded to have improved the participants' knowledge, understanding, and skills by an average of $81.25 \%$
\end{abstract}

Keywords: Solid waste, Compost

\begin{abstract}
Abstrak
Pertanian saat ini dilakukan dengan pertanian organik sehingga memerlukan pupuk kompos mengantikan pupuk kimia. Penggunaan pupukyang berbahan baku organik sangat dianjurkan, karena pupuk yang berbahan baku kompos dapat membantu unsur hara yang ada didalam tanah, selain itu kompos juga dapat dibuat dari bahan baku yang ada disekitar lingkungan kita. Dengan menggunakan kompos dapat membantu petani dalam menghemat biaya produksi, karena kompos dapat dibuat dari bahan baku yang tidak terpakai. Sebagai contohnya adalah kompos yang berasal dari kotoran sapi, biasanya tidak memiliki harga dan manfaat ternyata dapat dimanfaatkan sebagai bahan baku pembuatan kompos sehingga dengan pemanfaatan tersebut dapat mengurangi biaya produksi yang biasa dikeluarkan oleh petani. Tujuan dari pengabdian ini adalah untuk memberikan pengetahuan kepada mitra bahwa ternyata limbah peternakan yang mereka usahakan oleh mereka dapat digunakan sebagai bahan baku pembuatan kompos sehingga limbah peternakan yang berupa kotoran sapi dapat ditanggulangi dan juga dapat membantu para petani dalam mengurangi biaya yang dikeluarkan untuk usahatani yang juga mereka lakukan. Kompos yang berasal dari kotoran sapi sangat membantu dalam penyuburan tanah dan dapat dilihat langsung manfaatnya bagi tanaman dan tanah. Kesimpulan Pemanfaatan kotoran sapi menjadi kompos adalah untuk mengurangi limbah kotoran ternak, Kegiatan pengabdian masyarakat ini disimpulkan telah meningkatan pengetahuan, pemahaman, dan ketrampilan peserta baik dengan rata-rata $81,25 \%$.
\end{abstract}

Kata kunci: Kotoran Sapi, Kompos

\section{PENDAHULUAN}

Kecamatan Rumbai merupakan kecamatan yang banyak peternak sapi di kota Pekanbaru ; Populasi sapi di kecamatan Rumbai 1130 ekor kambing 1150 ekor (BPS.2020) merupakan Kecamatan masyarakatnya melakukan usahatani diantaranya memelihara ternak sapi juga membeli ternak sapi sebagai tabungan dan untuk penggemukan yang saat hari raya idul adha dan idul fitri dapat di jual . Ternak sapi berperan dalam pemenuhan kebutuhan daging di Indonesia untuk memenuhi permintaan telah dilakukan berbagai cara dengan pemeliharaan sapi bagi peternak di seluruh daerah di Indonesia. Kebutuhan daging sapi paling banyak di penuhi oleh peternak rakyat yang memelihara sapi lokal,lokasi pengabdian pada masyarakat ini berjarak $2 \mathrm{~km}$ dari Kampus Universitas Lancang Kuning. Di kelompok tani usaha mandiri memiliki 81 ekor sapi jika satu ekor menghasilkan $4 \mathrm{~kg}$ kotoran sehari maka di kelompok ini mengashilkan $324 \mathrm{~kg}$ perhari ini merupakan potensi besar untuk dijadikan pupuk kompos ,selama ini belum 
dimanfaatkan menjadi kompos karena belum pernah dilatih mengolahnya hanya di tumpuk saja di sekitar kandang kemudian di berikan kepada tanaman disekitar tempat tinggal dan untuk tanaman pakan ternak.

Pandemi covid 19 menyebabkan banyak keluarga yang menanam bunga dan tanaman di pekarangan rumah yang membutuhkan pupuk maka kompos diperlukan untuk tanaman. Masyarakat sudah menyadari pupuk kompos lebih baik dipergunakan dari pada pupuk kimia karena dengan kompos dapat mengemburkan tanah dan unsur hara juga baik untuk memenuhi kebutuhan tanaman apalagi bunga yang berwarna jika diberi kompos akan meyebabkan warna lebih cerah dan lebih lebar daunnya.

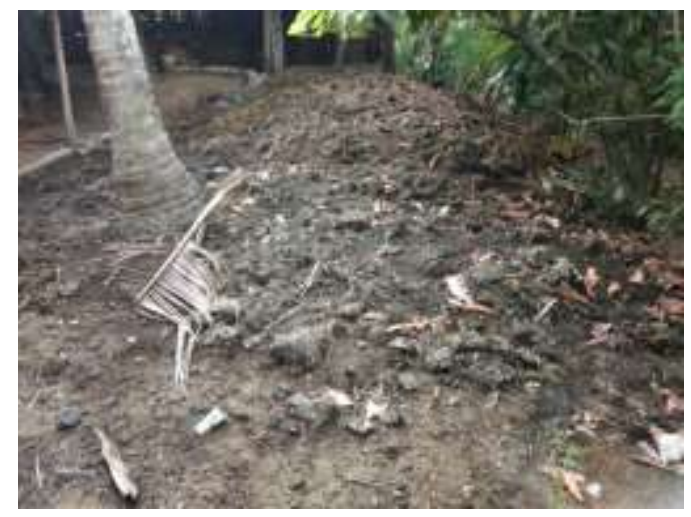

Gambar 1. Kotoran sapi di Kelurahan Umbansari

Pupuk organik sedang banyak diminati oleh masyarakat yang ada di Indonesia. Itu disebabkan pengetahuan masyarakat tentang kesehatan sudah berkembang. Pemakaian bahan kimia sudah mulai ditinggalkan oleh petani dalam penggunaannya dan sekarang petani mulai beralih dengan penggunaan pupuk dan pestisida alami. Keunggulan pupuk dan pestisida alami adalah lebih sehat dan menyuburkan tanaman dengan produksi lebih baik.

\section{METODE}

Metode yang digunakan dalam pengabdian masyarakat ini adalah:

1. Penyuluhan : pada kegiatan ini akan dijelaskan kepada kelompok tani bagaimana cara pembuatan pupuk kompos/ organik dari kotoran sapi. Didalam penyuluhan ini juga dilakukan sesi tanya jawab dan diskusi.

2. Demonstrasi : pada kegiatan ini juga dilakukan demonstrasi cara pembuatan pupuk kompos/ organik dari kotoran sapi .

Pada saat demonstrasi membuat pupuk kompos diperlukan bahan sebagai berikut, selain bahan juga ada tata cara pembuatan pupuk kompos/ organik sebagai berikut:

a. Bahan

- Bahan baku utama yang digunakan dalam pembuatan pupuk kompos adalah kotoran sapi $20 \mathrm{~kg}$.

- Bahan tambahan yang diperlukan adalah gula merah $1 \mathrm{~kg}$ atau tetes tebu 1 liter, sekam padi / serbuk gergaji $2 \mathrm{~kg}$. EM 4 .

b. Alat

- Drum plastik 1 buah

- Ember, pengaduk ,cangkul

- Skop.

Sebelum fermentasi pupuk kompos warnanya coklat kekuning-kuningan, baunya masih berbau kotoran, tetapi setelah difermentasi warnya berubah menjadi coklat kehitam-hitaman. 
3. Evaluasi : melaksanakan Pre Test dan Post Test untuk melihat sejauh mana pengetahuan peserta tentang cara demonstrasi cara pembuatan pupuk kompos/organik dari kotoran sapi. Adapun kriteria peningkatan pengetahuan peserta sebagai berikut:

$\begin{array}{ll}<50 \% & =\text { Sangat tidak baik } \\ 50 \%-59 \% & =\text { Tidak baik } \\ 60 \%-69 \% & =\text { Agak tidak baik } \\ 70 \%-79 \% & =\text { Agak baik } \\ 80 \%-89 \% & =\text { Baik } \\ >90 \% & =\text { Sangat Baik }\end{array}$

Pelatihan ini dilakukan dengan tujuan agar petani dapat mengetahui besarnya biaya yang harus dikeluarkan guna memenuhi kebutuhan kegiatan usahatani, juga bila ditekuni lebih lanjut pembuatan pupuk organik bisa dijadikan alternatif untuk menambah penghasilan. Pelatihan ini dilakukan dengan memberikan penyuluhan tentang cara pembukuan sederhana tentang penghitungan biaya dan penerimaan.

Kegiatan pendampingan dilakukan untuk memantau keterampilan petani dalam membuat pupuk kompos /organik. Untuk evaluasi hasil dari pupuk akan dilakukan setelah pembuatan kompos dilaksanakan. Evaluasi hasil dapat diketahui dari kualitas pupuk organik yang dihasilkan dengan memperhatikan ciri-ciri kompos yang baik seperti:

- Warna kompos coklat tua hingga hitam menyerupai warna tanah

- Tidak larut dalam air meski sebagian kompos dapat membentuk suspensi atau tidak mudah mengendap

- Mempunyai dampak positif pada tanah dan tanaman bila digunakan sebagai pupuk

- Suhunya sama dengan suhu lingkungan

- Remah dan mudah hancur

- Tidak berbau

Selain itu juga akan diedarkan kuisioner kepada anggota kelompok tani sebelum dan sesudah kegiatan, juga daftar hadir setiap kegiatan yang dilakukan

\section{HASIL DAN PEMBAHASAN}

Pengabdian pada masyarakat telah dilaksanakan pada tanggal 16 Januari 2021 , lokasi kegiatan di rumah peternak sapi bapak Bogimin .Peserta yang mengikuti kegiatan ini sangat antusias terutama pada saat kegiatan demonstrasi, seluruh peserta turut serta dalam mengolah kotoran sapi yang sudah dikumpulkan untuk dijadikan kompos.

\section{A. Penyadaran dan Sosialisasi}

Pertama kali tim memberikan penyadaran kepada peternak bahwa kotoran sapi dapat dibuat kompos yang dijadikan pupuk bagi tanaman perkebunan seperti kelapa sawit ,karet dan lainnya. Pupuk kompos yang berasal dari ternak sapi merupakan pupuk arganik yang baik untuk pertumbuhan dan pemeliharaan tanaman. Peseta semuanya adalah laki-laki karena yang memelihara ternak , juga semua peserta juga memiliki tanaman baik tanaman perkebunan dan tanaman hortikultura seperti ; sayur, buah banyak ditanam di kebun petani maka untuk mengurangi biaya pupuk maka dengan pupuk kompos dapat mengurangi biaya pembelian pupuk sehingga petani dapat keuntungan lebih banyak dan dapat mengemburkan tanah.

Setelah diberi penyadaran peserta sangat berminat menjadi pengusaha kompos dari kotoran ternak dan memanfaatkan limbah menjadi bermanfaat dan menambah pendapatan 
keluarga. Selama ini belum pernah memanfatkan limbah ternak menjadi kompos sehingga sangat memerlukan kegiatan ini untuk dilakukan langsung bermanfaat bagi petani dan peternak.
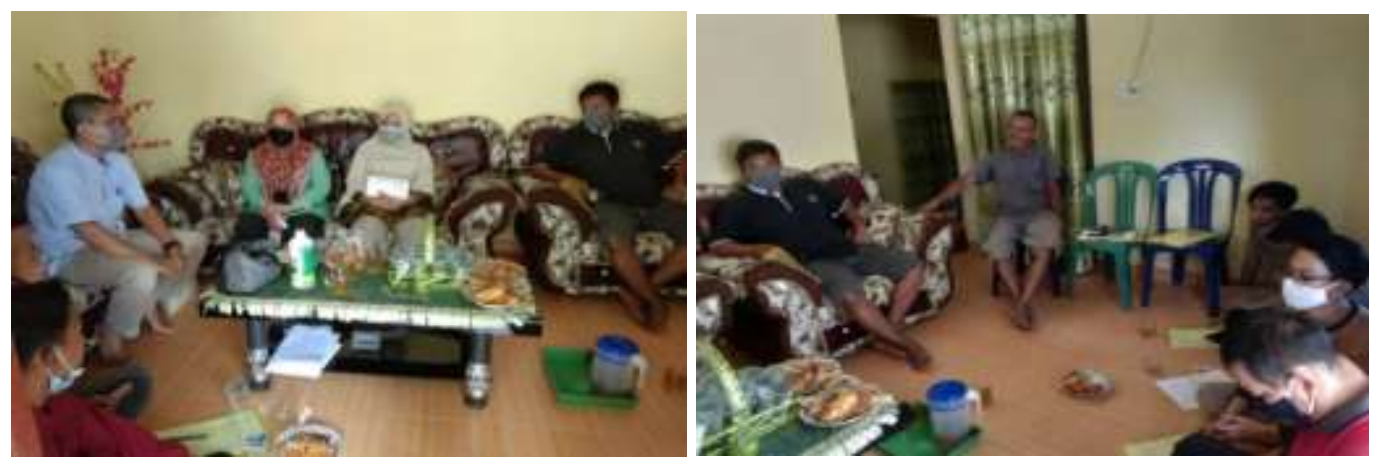

Gambar 2. Peserta Pelatihan Pegolahan Kototan Sapi Menjadi Kompos

B. Pelatihan pengolahan kotoran sapi menjadi kompos

Pada kegiatan pengabdian masyarakat ini Tim menggunakan bio aktifator agrismba. merupakan activator yang membantu kegiatan fermentasi kotoran sapi menjadi kompos. Bahan organik yang digunakan salah satunya adalah sekam padi, dimana diketahui bahwa sekam padi merupakan bahan organik yang lama proses penguraiannya, tetapi menghasilkan aerasi yang baik di lingkungan pengomposan, dan menyebabkan kelembaban menjadi rendah. Seperti yang dilaporkan oleh Ruslinda dan Aziz, (2004), bahwa penambahan serpihan kayu menyebabkan suhu dan kelembaban menjadi lebih rendah sehingga kondisi menjadi aerob, dan hal ini tidak dapat memenuhi kelembaban yang diharapkan yaitu di atas 50\%, dan $\mathrm{pH}$ tidak memenuhi persyaratan pengomposan.
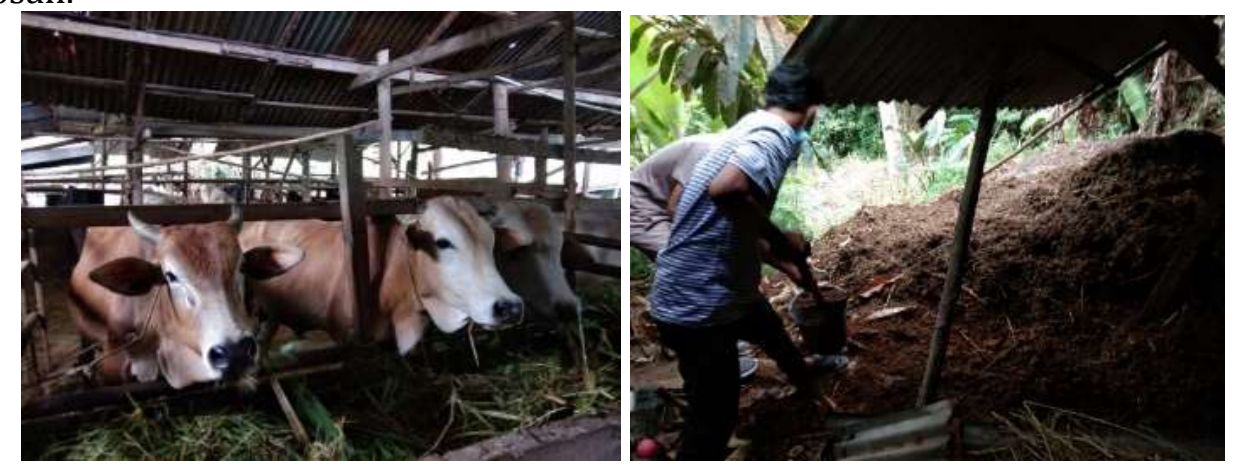

Gambar 3. Pengolahan Kotoran Sapi Menjadi Kompos
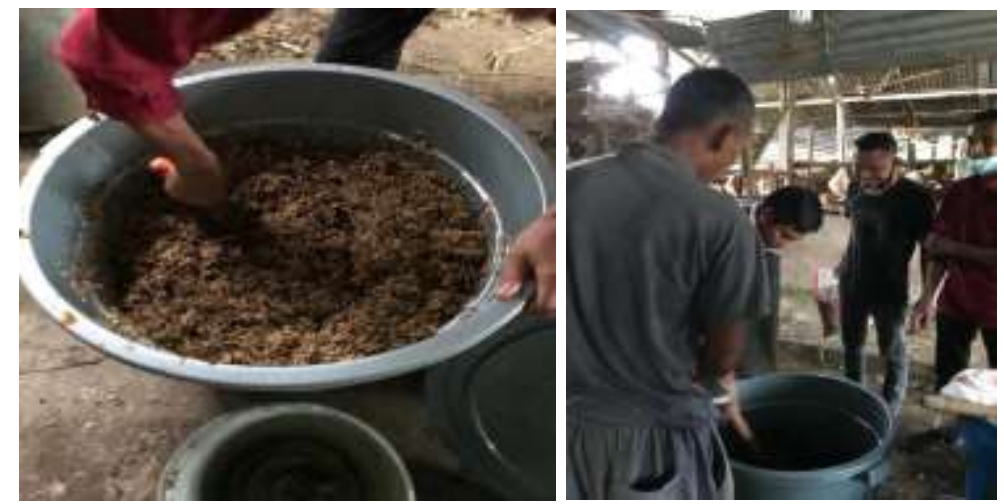

Gambar 4. Demonstrasi Pengolahan Kotoran Sapi Menjadi Kompos 


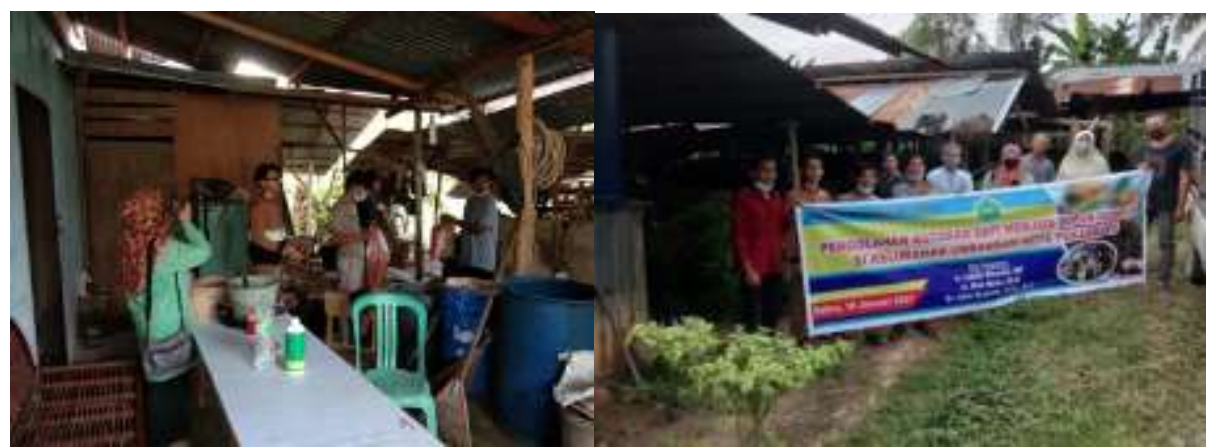

Gambar 5. Foto Bersama Pengolahan Kotoran Sapi Menjadi Kompos

C. Evaluasi

Setelah melalukan demosntrasi proses pengomposan pada minggu ke empat kompos sudah matang sesuai dengan ciri kompos yang sudah siap untuk dimanfaatkan untuk tanaman. Ciri Kompos Matang; Berwana coklat kehitam-hitaman.Tidak berbau busuk.Tekstur kompos, sedikit berserat halus.Kandungan air apabila dikepal kuat tidak menjadi bergumpal keras ketika kepalannya dibuka juga tidak terurai terlepas seperti pasir kering.Mengandung hara yang tersedia bagi tanaman. Kemampuan mengikat air tinggi

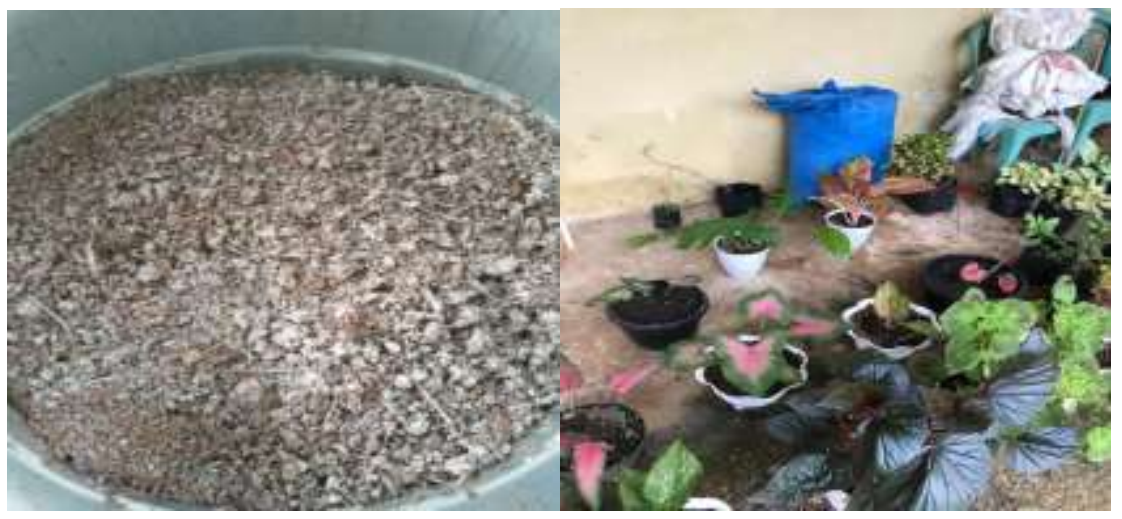

Gambar 6. Kompos Yang Sudah Matang Dan Bunga Diberi Kompos

Bahan kompos yang digunakan pada kegiatan ini. Anjuran pembuatan kompos starter digunakan baik itu berupa pupuk kandang atau kompos yang sudah jadi, agar proses pengomposan lebih cepat terlaksana, seperti yang dilaporkan oleh Sahwan dan Wahyono, (2011), kompos matang digunakan untuk menstimulir kerja komposter yang digunakan dalam menguraikan bahan organik yang dijadikan bahan kompos. Kompos yang baik akan mengalami penyusutan hampir 50\% dari berat semula, dan tetap lembab (Setyaningsih et al., 2017). Hasil evaluasi kuesioner sebelum dan sesudah kegiatan ditampilkan pada Tabel berikut:

Tabel 1. Rekap kuesioner sebelum dan Sesudah kegiatan.

\begin{tabular}{lccc}
\hline \multicolumn{1}{c}{ Kuesioner } & \multicolumn{3}{c}{ Jawaban (\%) } \\
\cline { 2 - 4 } & Sebelum & Sesudah & peningkatan \\
\hline Mengetahui limbah kotoran sapi & 12,5 & 100 & 87,5 \\
Mengikuti Pelatihan limbah kotoran sapi & 0 & 100 & 100 \\
Bahan untuk membuat kompos dari kotoran sapi & 0 & 100 & 100 \\
Alat yang digunakan untuk membuat kompos dari & 12,5 & 100 & 87,5 \\
kotoran sapi & & & \\
\hline
\end{tabular}




\begin{tabular}{lccc}
\hline Cara membuat kompos dari kotoran sapi & 12,5 & 100 & 87,5 \\
Memanfaatkan kompos dari kotoran sapi & 50 & 100 & 50 \\
Menyukai kotoran sapi sebagai pupuk & 75.00 & 100 & 25,00 \\
Berminat menjadi pengusaha kompos & 0 & 100 & 100 \\
Pernah membeli pupuk kompos kotoran sapi & 12.5 & 100 & 87,5 \\
Mengetahui lama proses kompos dapat dipakai & 12,5 & 100 & 87,5 \\
\hline
\end{tabular}

Sumber : olahan 2021

Pengabdian pada masyarakat yang dilakukan meningkatkan pengetahuan peserta seperti yang tercantum pada Tabel 2. Peningkatan yang terjadi berkisar antara 12,5 \%sampai 87,5\%, dengan rata-rata peningkatan $81,25 \%$.berarti baik . peningkatan yang beragam sesuai dengan pengetahuan peserta dan keseriusan peserta dalam menyimak penjelasan yang diberikan.lebih tinggi dari Pengabdian Nurwati,N , Siswati ,L.mufti (2017) peningkatan pengetahuan pada pembuatan pupuk organik dari kotoran sapi meningkat 70\%.. Sedangkan Suprapto et al., (2017), melaporkan bahwa kurangnya pengetahuan masyarakat tentang penangan limbah menjadi sesuatu yang bermanfaat perlu sosialisasi yang berkesinambungan. Suhastyo, dan Asriyanti, (2017) melaporkan bahwa terjadi peningkatan pengetahuan peserta dan peningkatan ketrampilan dalam memanfaatkan kotoran sapi menjadi kompos.

Kotoran sapi jika dijadikan pupuk Kompos juga memiliki potensi yang sangat berguna untuk menjaga kesuburan tanah dan menciptakan hasil panen yang maksimal dalam dunia pertanian.(LA wardana dkk.2021)

Keunggulan Pemanfaatan Limbah kompos/organik ;Hasil panen lebih tahan disimpan, lebih berat, lebih segar, dan lebih enak.Mengandung hormon dan vitamin bagi tanaman Menghemat biaya kelola limbah,Mengurangi volume/ukuran limbah,Memiliki nilai jual yang lebih tinggi dari pada bahan asalnya ,Mengurangi polusi udara.

Pada kegiatan pengabdian kepada masyarakat di Kelurahan Umbansari ini ada faktor pendukung dan penghambat untuk dapat memanfaatkan limbah kotoran sapi menjadi kompos banyak rumah tangga memiliki ternak sapi sebagai bahan baku kompos, sedangkan petani sebagian besar menggunakan pupuk kimia untuk tanamannya sesuai dengan pendapat .(Sutrisno 2019)Faktor PendukungYang menjadi faktor pendukung dalam kegiatan pengabdian ini adalah: a)Pupuk Kandang mempunyai banyak manfaat.b)Bahan baku dalam pembuatan pupuk kandang mudah didapatkan .Faktor Penghambat a)Mayoritas petani desa ini adalah petani yang terbiasa menggunakan pupuk kimia yang lebih besar dibandingkan pupuk kandang.b)Mayoritas petani desa ini masih memerlukan informasi dan pendidikan terlebih lagi dalam hal pengemasan dan pemasaran.

Pelatihan pemanfaatan limbah kotoran sapi menjadi kompos agar masyarakat dapat memanfaatakan kotoran sapi menjadi pupuk bagi tanaman dan menjaga kebersihan lingkungan Sesuai dengan (Wianto ,2020) program penyuluhan pemanfaatan limbah ternak sapi menjadi pupuk kompos kepada masyarakat adalah masyarakat Duman dapat mengolah limbah dan sampah organik untuk dijadikan sebagai pupuk pertanian. Selain mengunakan biaya yang sedikit juga dapat menjaga kebersihan lingkungan yang sehat dan indah dan masyarakat berkoitmen untuk upaya mengembangkan berkelanjutan program

\section{KESIMPULAN}

Pemanfaatan kotoran sapi menjadi kompos adalah untuk mengurangi limbah kotoran ternak, Kegiatan pengabdian masyarakat ini disimpulkan telah meningkatan pengetahuan, pemahaman, dan ketrampilan peserta rata-rata $81,25 \%$ baik . ulan harus mengindikasi secara jelas hasil-hasil yang diperoleh, kelebihan dan kekurangannya, serta kemungkinan pengembangan selanjutnya. 


\section{UCAPAN TERIMA KASIH}

Ucapan terimakasih ditujukan kepada Lurah Umbansari yang telah memberikan kesempatan untuk melakukan kegiatan pengabdian di wilayah administratifnya, dan terimakasih diucapkan kepada pimpinan Unilak dan Fakultas Pertanian yang telah memberikan bantuan finansial dalam melaksanakan kegiatan ini.

\section{DAFTAR PUSTAKA}

Ariyanto,S.E..Perbaikan Kualitas Pupuk Kandang Sapi dan Aplikasinya pada Tanaman Jagung Manis (Zea mays saccharata sturt). Staf pengajar Fakultas Pertanian UMK. Jurnal Sains dan Teknologi

Abidin, I. Z. (2008). Penggemukan sapi potong. AgroMedia

Affandi.2008. Pemanfaatan urine Sapi yang Difermentasi sebagai Nutrisi Tanaman.

Dahono.2012. Pembuatan Kompos Dan Pupuk Cair Organik Dari Kotoran Dan Urin Sapi.LPTP Kepulauan Riau.

Badan Pusat Statistik .2020. Rumbai dalam Angka 20

Djaja W. 2008. Langkah Jitu Membuat Kompos Dari Kotoran Ternak Dan Sampah.

Murbandono.L. 2002. Membuat Kompos .Penebar Swadaya. Jakarta.

Nurwati, N., Siswati, L., \& Mufti, M. (2017). Pelatihan pembuatan pupuk organik dari kotoran sapi di kelurahan tebing tinggi okura kota pekanbaru. Dinamisia: Jurnal Pengabdian Kepada Masyarakat, 1(1), 84-89

Indriani. Y.H. 2003.Membuat Kompos Secara Kilat. PT Penebar Swadaya, anggota IKAPI. Jakarta .

Krisno A. 2011. Peranan Mikroorganisme Pada Fermentasi Pembuatan Pupuk Kandang Dari Urine sapi.Http://Aguskrisno In Uncategoriz.

Suhastyo, A. A., Agroteknologi, P. S., Banjarnegara, P., \& Tengah, J. (2017). Pemberdayaan Masyarakat Melalui Pelatihan Pembuatan Pupuk Kompos. J.Pengabdian Dan Pemberdayaan Masyarakat, 1(2).

Sutrisno, E., \& Priyambada, I. B. (2019). Pembuatan pupuk kompos padat limbah kotoran sapi dengan metoda fermentasi menggunakan bioaktivator starbio di Desa Ujung-Ujung Kecamatan Pabelan Kabupaten Semarang. Jurnal Pasopati: Pengabdian Masyarakat dan Inovasi Pengembangan Teknologi, 1(2).

Wardana, L. A., Lukman, N., Mukmin, M., Sahbandi, M., Bakti, M. S., Amalia, D. W., ... \& Nababan, C. S. (2021). Pemanfaatan Limbah Organik (Kotoran Sapi) Menjadi Biogas dan Pupuk Kompos. Jurnal Pengabdian Magister Pendidikan IPA, 4(1

Wiantoro, K. U., Baehaki, A., \& Mulyati, M. (2020). Pemanfaatan Limbah Ternak Sapi Menjadi Pupuk Kompos Di Desa Duman, Kecamatan Lingsar Kabupaten Lombok Barat. Jurnal Warta Desa, 2(1).

Zenzen Zainudin.2016. Cara Membuat Pupuk Kandang Yang Baik Dan Benar. Agrotani.Com 